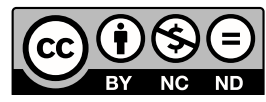

Estudos Teológicos foi licenciado com uma Licença Creative Commons Atribuição - NãoComercial - SemDerivados 3.0 Não Adaptada

http://dx.doi.org/10.22351/etv59i2.3780

\title{
MÉTODO HISTÓRICO-CRÍTICO: UM OLHAR EM PERSPECTIVA ${ }^{1}$
}

\author{
Historical-Critical Method yesterday and today
}

Flavio Schmitt ${ }^{2}$

Resumo: A origem do método histórico-crítico está diretamente ligada à leitura científica da Bíblia. Não obstante a leitura científica da Bíblia praticada, especialmente nos centros de formação acadêmica, existem inúmeras outras formas de lidar com um texto bíblico, inclusive na perspectiva científica. Contudo, uma certa pretensão de hegemonia tem colocado o método histórico-crítico no centro de inúmeras polêmicas, desde a relativização do objeto com o qual o método se ocupa, passando pelo distanciamento provocado com a realidade eclesial, até a acusação de ateísmo. Usuários do método histórico-crítico o entendem como científico, racional e acadêmico. Críticos o apontam como moderno, liberal e profano. Embora o locus privilegiado do método seja a academia e os centros de pesquisa bíblica, os aportes do método pretendem estar a serviço da igreja e de sua causa. Este artigo discute aspectos relacionados com o método histórico-crítico e sua compreensão. Primeiramente investiga a origem e o desenvolvimento do método. Na sequência discute algumas características do mesmo. Por fim, aponta elementos a serem considerados na compreensão e emprego do método. Trata-se de um trabalho de revisão bibliográfica, que tem como objetivo contribuir na discussão acerca do instrumental de estudo e interpretação da Bíblia.

Palavras-chave: Método histórico-crítico. Exegese. Bíblia. Ciência.

Abstract: The beginning of the Historical-Critical Method is directly linked to is directly linked to the scientific reading of the Bible. Notwithstanding the scientific reading of the Bible practiced, especially in academic training centers, there are countless other ways to deal with a biblical text, even from the scientific perspective. However, a certain claim to hegemony has placed the Historical-Critical Method in the center of the target of countless controversies, since object relativization of the object with which the method deals, passing through the distancing caused by ecclesial reality, even the accusation of atheism. Users of the Historical-Critical Method understand it as scientific, rational and academic. Critics point him out as modern, liberal and profane. Although the privileged locus of the method be the academy and the biblical research centers, the contributions of the method are intended to be of service to the Church and her cause. This article discusses aspects related to the Historical-Critical Method and its comprehension. First investigate the origin and development of the method. Following

1 O artigo foi recebido em 22 de agosto de 2019 e aprovado em 03 de outubro de 2019 com base nas avaliações dos pareceristas ad hoc.

2 Doutor. Faculdades EST, São Leopoldo, RS. E-mail: Flavio@est.edu.br 
discusses some of the features of it. Finally, it points out elements to be considered in understanding and use of the method. This is a bibliographic review work which aims to contribute to the discussion about the tools of Bible study and interpretation.

Keywords: Historical-Critical Method. Exegesis. Bible. Science.

\section{Introdução}

Muitas e variadas têm sido as críticas desferidas contra o método histórico-crítico. ${ }^{3}$ Também não é de hoje que essas críticas se fazem sentir. Também não é sem razão que, de diferentes frentes, as críticas estejam sendo desferidas. Por isso não há como deixar de falar de um método crítico sem crítica. A crítica é inerente ao método. Talvez por isso mesmo os usuários do método se sintam tão confortáveis com as críticas que lhes são dirigidas.

Contudo, nem tudo está resolvido ao se admitir que a crítica rima com método histórico-crítico. Pelo contrário, ao admitir a crítica como uma questão inerente ao método, um largo caminho se abre à discussão. Longe de juízos apressados, uma crítica ao método exige, no mínimo, uma familiaridade com suas origens e as pretensões de seus idealizadores e os objetivos que pretende alcançar.

Não se trata de ser contra ou a favor do que hoje se entende por método histórico-crítico. Também não é uma questão que possa ser resolvida com preferências ou categorias subjetivas, por mais subjetivas que sempre sejam as opções humanas. Para além de paixões e genitivos, o método histórico-crítico é um convite à reflexão, ao discernimento do que humanamente é possível conceber em termos de interpretação, compreensão e sentido da vida, e dos textos bíblicos que lhe dão sustentação.

$\mathrm{O}$ método histórico-crítico tem sido definido como um método exegético. É um método usado na análise diacrônica da Bíblia. Está a serviço do estudo e da interpretação da Bíblia e do fazer teológico dela decorrente.

Uma das experiências humanas mais degradantes para uma pessoa é ser enganada por uma religião. Por serem portadoras de valores e sentidos últimos da vida, espera-se que as religiões não falhem. Na mensagem que veiculam são depositadas algumas das crenças e valores mais nobres que um ser humano pode alimentar. Ainda que possa haver unanimidade em torno dessa questão, o desafio maior, no entanto, está em como proceder para que, seja de forma involuntária ou intencional, as religiões não enganem, não transmitam algo que não possam sustentar a partir de seus textos.

\footnotetext{
Fitzmyer relaciona vários artigos e livros em diferentes línguas que atacam o método histórico-crítico. Cf. FITZMYER, Joseph A. A interpretação da Escritura: em defesa do método histórico-crítico. São Paulo: Loyola, 2011. p. 73. A esse já considerável volume de textos podem ser acrescentados ainda os artigos de Augusto Nicodemos Lopes (LOPES, Augustus Nicodemus. O Dilema do método histórico-crítico na Interpretação Bíblica. Fides Reformata, São Paulo, ano X, n. 1, p. 115-138, 2005) e João Oliveira Ramos Neto (NETO, João Oliveira Ramos. Os Problemas e os Limites do Método Histórico-Crítico. Theos, Campinas, 6. ed., v. 5, n. 2, p. 1-12, dezembro de 2009).
} 
Ao chegar ao terreno da credibilidade, não obstante todos os limites e limitações inerentes a esse esforço, não há como deixar de reconhecer o papel desempenhado pela história, por mais ambígua e contraditória que possa ser seu legado, especialmente quando apreciado em retrospectiva e num passado distante. Ao situar o papel ou relevância da história para o estabelecimento de um certo nível de segurança na insegurança das possibilidades de interpretação dos fatos e textos, o ser humano acerca-se de um recurso que lhe confere uma margem de sentido relativamente confiável.

O mesmo se pode dizer do método. Um método, como ponto de partida para chegar a algum lugar, como espaço cronológico, virtual e físico a ser percorrido, oferece o caminho para alcançar o objetivo de compreender o texto bíblico.

Ainda que do ponto de vista teórico possa haver consenso acerca da importância da crítica, da perspectiva histórica e da importância do método, para o entendimento de algo humanamente inteligível, o mesmo não se pode dizer do método histórico-crítico. A razão desse desencontro reside basicamente no fato do método histórico-crítico ressignificar o sentido e a finalidade da crítica, do método e da história. O que o método histórico-crítico faz, na verdade, é conferir uma epistemologia própria à crítica, ao método e à história.

Como mostra sua história, o método histórico-crítico se desenvolveu lançando mão de critérios e conceitos concebidos à margem da investigação bíblica. Como afirma Lopes, "como qualquer método de interpretação, ele faz uso de alguns princípios e regras que são derivados do bom senso, da razão e da lógica, e que não são propriedade de nenhuma hermenêutica em particular"4.

O presente texto discute as possíveis origens do método histórico-crítico, apresenta suas principais características e pondera acerca de aspectos a serem considerados na tentativa de vislumbrar, em perspectiva, os alcances e limites do mesmo.

\section{As origens}

Por conta da centralidade atribuída à Escritura no movimento da Reforma, pesquisadores atribuem os primeiros impulsos relacionados com uma análise histórica dos textos bíblicos necessariamente a esse movimento. Além de desencadear uma forma diferente de acercamento ao texto, diferente do que vinha sendo praticado até então, o movimento da Reforma também desencadeia uma compreensão da Escritura que iria determinar todo um desenvolvimento posterior de leitura e interpretação da mesma.

Tanto o estabelecimento de critérios para a interpretação bíblica como a perspectiva crítica ao próprio texto bíblico adotada pelos reformadores descortinam uma forma nova de relação e tratamento da Escritura. A Reforma, ao postular que a Escritura é a única fonte de revelação, "coloca-a como centro das atenções e desencadeia com isso o surgimento da ciência bíblica. Tal concentração na Escritura leva, por

4 LOPES, 2005, p. 117. 
outro lado, a um posicionamento crítico frente à Escritura que desembocará na análise histórico crítica da bíblia"5.

Como é próprio de uma reflexão teológica inserida na realidade a partir de onde adquire visibilidade, a mudança é uma constante e necessária. Nesse sentido, também o surgimento do método histórico-crítico está relacionado com as mudanças que ocorrem na sociedade e no estudo da Bíblia. De forma direta, "o método histórico-crítico é uma forma de tornar a interpretação bíblica compatível com o mundo e o modelo científico da época" 6 .

Para Volkmann, as “descobertas do homem, cuja mente não cabia mais na prisão dos dogmas eclesiásticos, levam à revolução na cosmovisão e a uma sempre maior autonomia do pensamento humano capaz de desenvolver mais e mais a ciência e levar a novas descobertas".

Na medida em que a compreensão da natureza e da história não está mais condicionada pela normatividade da Bíblia, uma nova racionalidade emerge como paradigma. Contudo, esse referencial, resultante de uma nova cosmovisão gestada a partir do século XVI, irá impactar o estudo e a pesquisa da Bíblia somente dois séculos depois.

Do ponto de vista histórico, além da inflexão provocada na leitura e estudo da Bíblia pelo movimento da Reforma, a contribuição dos ideais renascentistas, com sua volta às fontes (recursos ad fontes), e mais tarde, do próprio movimento iluminista e o papel desempenhado pela ciência, são decisivos para compreender o que acontece com a Bíblia. Como nos diz Adolfo Sanchez Vasquez, acerca do período moderno, "na nova sociedade consolida-se um processo de separação daquilo que a Idade Média unira: a) a razão separa-se da fé (filosofia, da teologia), b) a natureza, de Deus (ciências naturais, dos pressupostos teológicos), c) o Estado, da Igreja, d) o homem, de Deus"7. Nesse sentido, o método histórico-crítico tem na sua origem a influência de um contexto histórico em transformação, particularmente do racionalismo na filosofia e do deísmo na teologia.

Segundo Lopes: "Da Renascença, o método histórico-crítico absorveu a ênfase no humano em detrimento do divino. Do ceticismo francês, a dúvida como pressuposto dogmático e metodológico. E do Iluminismo, a razão em detrimento da revelação"s.

Como impulsos decisivos para uma mudança de paradigma na interpretação bíblica cabe mencionar a influência de pensadores deístas como Jean Turrettini e Johann Ernesti, que sugerem que o texto bíblico deva ser interpretado como a racionalidade humana costuma interpretar qualquer outro livro. ${ }^{9}$

\footnotetext{
5 VOLKMANN, Martin; DOBBERAHN, Friedrich Erich; CÉSAR, Ely Éser Barreto. Método históricocrítico. São Paulo: CEDI, 1992. p. 12.

6 VOLKMANN; DOBBERAHN; CÉSAR, 1992, p. 26.

7 SÁNCHEZ VÁSQUEZ, Adolfo. Ética. Rio de Janeiro: Civilização Brasileira, 1978. p. 247.

8 LOPES, 2005, p. 118.

9 Em seu Tratado sobre o Método de Interpretação da Bíblia, Jean Turrettini defende seu ponto de vista. Johann Ernesti sugere considerar a diferença histórica entre os testamentos. Cf. VOLKMANN; DOBBERAHN; CÉSAR, 1992, p. 27.
} 
O rompimento definitivo com a tutela doutrinária da tradição ortodoxa é desencadeado por aquele que é considerado o pai do método histórico-crítico. Ao partir da premissa de que palavra de Deus e Escritura não são idênticas e que o cânon não é incontestável, Johann Semler (1725-1791) desencadeia um processo de secularização da leitura do texto bíblico, cujo prazo de validade ainda não está esgotado. Para esse autor, importa analisar e perscrutar o texto em seu significado histórico. Somente num segundo momento, cabe dizer o conteúdo dos textos para os dias atuais.

As premissas de Semler ${ }^{10}$, inspiradas nos ares da Revolução Francesa que estava por vir, colocam outro horizonte para a análise dos textos bíblicos. Além de sugerir que os textos devam ser analisados em perspectiva histórica, propõe que o texto seja compreendido em sua inserção histórica, como testemunho de um tempo passado. Essa ênfase no aspecto histórico leva Semler a distinguir entre Antigo e Novo Testamento como duas grandezas diferentes. Da mesma maneira, propõe distinguir os tempos e grupos entre os escritos da cristandade primitiva. Com Semler, "o próprio autor do texto bíblico passa a ser objeto da pesquisa histórica"11.

A partir de Semler, a pesquisa bíblica passa a considerar que:

- a Bíblia como livro não é a Palavra inspirada de Deus;

- o cânone de livros sagrados é uma grandeza histórica que deve ser analisada criticamente;

- cada um dos livros deve ser visto em sua inserção histórica e como testemunho dessa história passada. ${ }^{12}$

Assim como antes de Semler houve impulsos em direção ao estabelecimento de um método histórico e crítico, depois de Semler essas contribuições passaram a ser ainda mais abundantes e consistentes.

Nos séculos XVII e XVIII, o método histórico-crítico desenvolveu-se mais, pelo esforço do jurista e teólogo holandês Hugo Grotius, do oratoriano e biblista francês Richard Simon e do filósofo holandês Baruch Spinoza - portanto, pela obra de um protestante, um católico e um judeu. ${ }^{13}$

Estudos posteriores tornaram possível uma distinção maior entre autores e redatores da Bíblia, bem como a determinação dos primeiros destinatários e seus contextos de vida. Além disso, os estudos histórico-críticos trouxeram uma nova maneira de compreender a Bíblia em sua dimensão histórica, literária e teológica.

${ }^{10} \mathrm{Na}$ Institutio ad Doctrinam Christianam Liberaliter Discendum - Instituição de uma maneira mais liberal de aprendizado da doutrina cristã, de 1774, em lugar de uma doutrina uniforme da Bíblia, Semler argumenta a favor da polifonia dos escritores bíblicos, oriundos de diferentes épocas e tradições. VOLKMANN; DOBBERAHN; CÉSAR, 1992, p. 48.

11 VOLKMANN; DOBBERAHN; CÉSAR, 1992, p. 29.

12 VOLKMANN; DOBBERAHN; CÉSAR, 1992, p. 29.

13 FITZMYER, 2011, p. 76. 
A influência do pensamento iluminista, especialmente nos estudos relacionados com o Jesus histórico (Hermann Samuel Reimarus, Ferdinand Christian Baur, David Friedrich Strauss, Bruno Bauer), bem como as contribuições da pesquisa e descobertas arqueológicas ainda estão a ecoar no estudo histórico crítico da Bíblia. ${ }^{14}$

\section{Características}

O método histórico-crítico apresenta-se, por um lado, como método exegético e teológico e, por outro, como uma epistemologia. Como método exegético, desdobra-se em passos metodológicos a serem desenvolvidos no estudo e análise do texto bíblico. Como epistemologia, reúne um conjunto de pré-conceitos que determinam os pressupostos teóricos levados em consideração no processo de acercamento e interação com o texto.

\section{O método como exegese}

O método histórico-crítico, do ponto de vista da exegese, é histórico porque lida com eventos históricos que, no caso da Bíblia, datam de muitos anos anteriores ao nosso tempo. Além disso, retrata a historicidade da formação do próprio texto. Por conta desse distanciamento temporal, a busca pela historicidade dos textos protege-o contra uma eventual manipulação do seu sentido por interesses ou interpretações subjetivas ou ideológicas.

O método histórico-crítico é um método por pressupor que para chegar ao entendimento de algo é preciso seguir por um caminho. É através de um método, no procedimento próprio da ciência, que a verificação histórico-crítica revela toda a sua cientificidade. Ao fazer do texto um objeto de investigação, o método histórico-crítico recorre ao método para compreendê-lo.

O método tem no horizonte a busca pelo sentido do texto em sua origem histórica. Por ser um texto de um contexto diferente do atual, o método histórico-crítico

É um método histórico, em primeiro lugar, porque lida com fontes históricas que, no caso da Bíblia, datam de milênios anteriores a nossa era. Em segundo lugar, porque analisa estas mesmas fontes dentro de uma perspectiva de evolução histórica, procurando determinar os diversos estágios da sua formação e crescimento, até terem adquirido sua forma atual. E, em terceiro lugar, porque se interessa substancialmente pelas condições históricas que geraram estas fontes em seus diversos estágios evolutivos ${ }^{15}$.

${ }^{14}$ Sobre uma história do método, ver DOBBERAHN, Friedrich Erich. Sobre a História do Método HistóricoCrítico. In: VOLKMANN; DOBBERAHN; CÉSAR, 1992, p. 37-72.

15 WEGNER, Uwe. Exegese do Novo Testamento: Manual de Metodologia. São Leopoldo: Sinodal, 1998. p. 17. 
É crítico na perspectiva do discernimento. Na linha dos teóricos da suspeita ${ }^{16}$, recomenda não tomar como óbvias as categorias com as quais opera. Pressupõe um juízo fundamentado na racionalidade, especialmente onde as fontes históricas apresentam lacunas e o testemunho bíblico por vezes se mostra diversificado e contraditório. Não há como negar que os "textos bíblicos possuem uma história de redação e tradição que dificultam a interpretação e a compreensão de sua mensagem"17.

Segundo Carson,

A essência da crítica, no melhor sentido dessa palavra tão mal usada, é a justificação de opiniões. Uma interpretação crítica das Escrituras é aquela que possui justificação adequada - lexical, gramatical, cultural, teológica, geográfica ou de qualquer outro tipo. Em outras palavras, exegese crítica neste sentido é aquela que dá boas razões para as escolhas que faz e as posições que adota ${ }^{18}$.

Como método exegético, o método lança mão de passos a serem seguidos. Desta forma, o método histórico-crítico alimenta-se de procedimentos e recursos presentes nos mais remotos tratamentos dispensados a textos escritos e incorpora procedimentos novos para a época em que passa a ser empregado no acesso à Bíblia.

Como afirma Fitzmyer, "alguns elementos do método histórico-crítico foram desenvolvidos por filólogos e comentadores gregos dos escritos de Homero e outros clássi$\cos [\ldots]^{\prime \prime 19}$. Essa herança metodológica herdada dos gregos influenciou a maneira dos pais da igreja ${ }^{20}$ de lidarem com os textos hebraicos do Antigo Testamento e gregos do Novo Testamento. O percurso histórico, passando pelo Renascimento, Reforma e Modernidade, permite afirmar que o método histórico-crítico é resultado de todo um esforço por tornar compreensível, em cada novo contexto, o que as palavras de Bíblia dizem.

Como ponto de partida, o método vale-se de dois elementos preliminares da filologia clássica. O primeiro trata da pergunta pela autenticidade do escrito (relacionada com a autoria, época, lugar, data de composição, conteúdo, estilo, forma literária, ambiente, destinatários). O segundo elemento diz respeito à crítica textual (pergunta pela transmissão do texto na língua original e nas versões).

Relacionado com a filologia, também está a importância dada pelo método histórico-crítico à tradução do texto bíblico. Embora os autores que discorrem sobre o método histórico-crítico não tenham se debruçado sobre o papel da tradução dos textos

${ }^{16}$ A expressão "mestres da suspeita" foi cunhada pelo filósofo francês Paul Ricoeur (1913-2005) para designar os pensadores Marx, Nietzsche e Freud. Segundo Ricoeur, foram esses três pensadores que suspeitaram das ilusões da consciência. RICOEUR, Paul. Da Interpretação: ensaio sobre Freud. Rio de Janeiro: Imago, 1977.

17 JUNGES, Fábio César; KONZEN, Leo. O método histórico-crítico de Interpretação bíblica. Vivências, Santo Ângelo, v. 4, n. 5, p. 101-113, out. 2007. p. 101.

${ }^{18}$ Cf. CARSON, D. A. A exegese e suas falácias. São Paulo: Vida Nova, 1992. p. 14.

19 FITZMYER, Joseph A. A Bíblia na Igreja. São Paulo: Loyola, 1997. p. 19.

${ }^{20}$ Zenódoto de Éfeso, diretor da biblioteca de Alexandria em 284 a.C., compilou um Glossário, estudo das palavras difíceis, de Homero. A Héxapla de Orígenes não deixa de ser um esforço crítico. Estudos críticos semelhantes foram desenvolvidos por Jerônimo e Agostinho (De Doctrina Christiana e De Consensu Evangelistarum). FITZMYER, 1997, p. 20. 
em hebraico e grego para o método histórico-crítico, ela é pressuposta. Não somente é pressuposta como parte do método, como recebe importância decisiva, principalmente a partir do resgate das línguas bíblicas na época da Reforma, como nas observações de Schleiermacher acerca da importância da filologia na interpretação do texto. ${ }^{21}$

Com o desenvolvimento da crítica histórica, outras ferramentas foram sendo agregadas ao método. A própria crítica literária, representada nos elementos preliminares anteriormente apontados, tem seu papel relacionado com a crítica histórica. Ao perceber que o autor do texto se valeu de recursos literários próprios de sua língua e época, ainda que o aspecto histórico não tenha sido sua preocupação principal, essa presença afeta o julgamento histórico do próprio texto.

Outro elemento importante da crítica histórica está relacionada com a crítica das fontes. As teorias científicas acerca das fontes do Pentateuco e dos evangelhos, por exemplo, abarcam um universo de compreensão que somente um estudo crítico, científico e acadêmico é capaz de comportar. Ainda que ao final o método diacrônico não disponha de mais material do que aquele que também está disponível para qualquer método sincrônico, a perspectiva histórica da abordagem do texto conduz a resultados diferentes na compreensão e interpretação do texto.

$\mathrm{Na}$ crítica das formas, o que a rigor não deixa de ser também uma crítica literária, e que alcança identidade na expressão Formgeschichte, reside um dos aportes mais significativos ao estudo científico da Bíblia e, ao mesmo tempo, um de seus calcanhares de Aquiles. Ao argumentar que o texto bíblico é resultado da justaposição de unidades literárias originalmente autônomas (perícopes), e que para estudo e compreensão de um texto é preciso decompô-lo em tantas partes quantas for divisível, o método histórico-crítico corre o risco de ir tão fundo ao poço, a ponto de esquartejar textos e unidades literárias de tal maneira, que sua unidade se perde no horizonte da compreensão.

Os esforços de Hermann Gunkel no estudo dos livros de Gênesis e Salmos ${ }^{22}$ e de Martin Dibelius e de Rudolf Bultmann ${ }^{23}$ com os evangelhos sinóticos seguramente aportaram novas luzes acerca da natureza literária dos textos bíblicos. Ao identificar formas e gêneros literários (Gattungen), os estudos também permitem identificar fases no processo de surgimento do texto bíblico. Além de identificar diferentes formas e formatos de texto, nesse processo também é investigado seu lugar vivencial, seu Sitz im Leben. Nessa direção, a crítica da forma tem entre seus objetivos “descobrir as formas originais dos textos bíblicos, ainda em sua fase oral de transmissão, antes de serem submetidos à escrita"24.

21 VOLKMANN; DOBBERAHN; CÉSAR, 1992, p. 50.

${ }^{22}$ Como representante da Religionsgeschichtliche Schule - Escola da História das Religiões, Gunkel submeteu o texto bíblico a uma análise literária aplicável a qualquer outro texto literário. GUNKEL, Hermann. Genesis. 6. Aufl. Berlin: Evangelische Verlagsanstalt, 1963.

${ }^{23}$ DIBELIUS, Martin. Die Formengeschichte des Evangeliums. 3. durchges. Aufl. mit einem Nachtrag von Gerhard Iber ed. Tübingen: J. C. Mohr, 1959. BULTMANN, Rudolf Karl. Die Geschichte der synoptischen Tradition. 7. durchgesehene Aufl. Göttingen: Vandenhoeck \& Ruprecht, 1967.

${ }^{24}$ LOPES, 2005, p. 125. 
Diferente é o tratamento dispensado pelo método histórico-crítico no que diz respeito aos aspectos redacionais de um texto. Na busca por determinar como os autores bíblicos, no uso de material da tradição, fizeram mudanças, revisões, redações e intervenções de acordo com seu interesse teológico e literário, surgiu a crítica redacional. O objeto da história da redação (Redaktionsgeschichte) está presente na linguagem e no estilo do autor bíblico.

Ao voltar sua atenção aos redatores, àqueles que utilizaram fontes orais e escritas e deram forma final ao texto, a crítica da redação parte do pressuposto que os evangelistas, por exemplo, são redatores que organizam o material disponível de acordo com determinado ponto de vista e intencionalidade.

Outros aspectos ligados ao método histórico-crítico continuam sendo acrescentados ao método por diferentes pesquisadores. Nessa perspectiva, cabe mencionar a análise retórica e a análise narrativa. ${ }^{25}$

Na América Latina, particularmente no que diz respeito à leitura sociológica da Bíblia $^{26}$ e leitura popular da Bíblia ${ }^{27}$, tem havido um intercâmbio construtivo na interação entre os elementos de análise histórico-crítica e a leitura sociológica e popular.

\section{O método como epistemologia}

Possivelmente a formulação mais clara dos pressupostos teóricos do método histórico-crítico tenham sido elaborados por Ernst Troeltsch. Embora do ponto de vista da história do desenvolvimento do método Troeltsch entre em cena somente no final do século XIX, sua contribuição sistematiza impulsos que já vinham sendo elaborados há mais tempo.

No tratado Sobre o Método Histórico e Dogmático da Teologia, em 1900², Troeltsch destaca os três princípios do pensar histórico-crítico:

- a crítica, ou seja, a dúvida metódica;

- a analogia, a chave para a crítica em todo acontecimento histórico;

- a correlação, a inter-relação entre os fenômenos da vida intelectual e histórica.

Troeltsch parte do princípio que no campo histórico só existem juízos prováveis. Segundo ele,

25 Fitzmyer destaca a importância do aspecto histórico e crítico para a análise retórica e narrativa. Cf. FITZMYER, 1997, p. 39ss.

${ }^{26}$ A leitura sociológica tem no aspecto histórico e no acercamento crítico ao texto um de seus pilares. Cf. WEGNER, Uwe. A Leitura Bíblica por meio do Método Sociológico. São Paulo: CEDI, 1993. 28 p. (Mosaicos da Bíblia; 12). Disponível em: < http://koinonia.org.br/protestantes/uploads/novidades/ Mosaicos-da-biblia_012.pdf $>$.

27 A leitura popular da Bíblia pressupõe os aportes históricos e críticos do método histórico-crítico. MESTERS, Carlos. O CEBI e sua metodologia de leitura bíblica. Por Trás da Palavra, v. 11, n. 64, p. 25-36, 1991.

28 TROELTSCH, Ernst. Sobre o Método Histórico e Dogmático da Teologia. São Leopoldo: Faculdade de Teologia, 1984. 
Os graus de probabilidade são distintos, vão do mais alto ao mais baixo. Em relação a cada tradição temos que medir o grau de probabilidade que lhe cabe. Com isso muda de princípio toda nossa postura em relação à enorme quantia de memórias e tradições de nossa, civilização, também ali onde nem se tenha efetuado correções do conteúdo e concepção ${ }^{29}$.

Cabe à crítica corrigir e alterar os conteúdos inacessíveis ao entendimento. Ainda assim, o "resultado alcançado, através deste processo de crítica, tão somente pode reivindicar um acerto provável" ${ }^{30}$.

O tratamento crítico dispensado aos textos parte de pressupostos.

Este pressuposto sustenta que no campo histórico não existem juízos absolutos, mas somente e sim, só juízos prováveis, sendo que o grau de probabilidade pode variar de acordo com o assunto. Isto implica em que também os resultados a que se pode chegar com a pesquisa histórica não podem reivindicar certeza absoluta, acertos absolutos. Em decorrência, os pesquisadores e as pesquisadoras apresentarão sempre uma dúvida metódica e eventuais questionamentos em relação àquilo que é objeto de suas análises. A aplicação deste pressuposto às tradições religiosas e bíblicas implica em que também os seus conteúdos e suas formas serão estudados criticamente, ou seja, serão submetidos a juízos de maior ou menor probabilidade histórica. ${ }^{31}$

Segundo Troeltsch, o que torna a crítica viável é a analogia. Além de essencial, é a analogia que possibilita a crítica histórica. "Segundo o princípio da analogia, a factibilidade histórica de fenômenos é tanto maior, quanto maior for a concordância entre estes e outros fenômenos facilmente atestáveis e verificáveis" "32.

Nas palavras de Troeltsch,

os fenômenos que a crítica pode reconhecer como tendo efetivamente ocorridos têm uma marca que os torna prováveis. Esta característica é sua concordância com fenômenos e situações normais, corriqueiras e diversas vezes atestadas e conhecidas. A verificação de analogias entre acontecimentos semelhantes do passado dá a possibilidade de atribuir-lhes probabilidade e de explicar o que é desconhecido num lugar pelo que é conhecido noutro lugar ${ }^{33}$.

Ao falar da correlação, Troeltsch parte do pressuposto de que todos os fenômenos se encontram numa relação de dependência mútua e recíproca. Há uma correlação entre todos os fenômenos da vida intelectual e histórica. Segundo ele, no estabelecimento da correlação entre fatos do passado e do presente, de um fenômeno para outro,

${ }^{29}$ TROELTSCH, 1984, p. 3.

${ }^{30}$ TROELTSCH, 1984, p. 4.

31 WEGNER, 1998, p. 18.

32 WEGNER, 1998, p. 18.

${ }_{33}$ TROELTSCH, 1984, p. 4. 
não pode haver mudança em um ponto sem que, anterior ou posteriormente, ocorra mudança em outro ponto, de sorte que todos os acontecimentos estão em um nexo contínuo e correlacionado, formando necessariamente um rio, no qual tudo e cada qual estão relacionados. Cada acontecimento está relacionado a outro. Com isso estão dados os princípios da explicação e concepção históricas ${ }^{34}$.

Decorre dessa compreensão que "a partir daí também a pesquisa bíblica é absorvida para dentro da história política, social e intelectual da antiguidade". Com esse referencial, a pesquisa bíblica passou a compreender elementos da religião de Israel a partir de manifestações religiosas semitas. "Através de crítica, analogia a correlação, o próprio método histórico conduz necessária e irrefreavelmente ao estabelecimento de um entrelaçamento e uma correlação entre as ações do espírito humano." ${ }^{35}$

Depois de todas essas considerações, Troeltsch ainda afirma:

Esta, a história, contém uma nova postura em relação ao intelecto humano e a suas produções ideais. Em todos os lugares o método histórico desaloja a antiga postura absoluta ou dogmática, que considerava determinadas situações e pensamentos como evidentes, tornando-os normas imutáveis e absolutas. O método histórico considera também aquilo que aparentemente é o mais evidente e os poderes que dominam o maior número de pessoas como produtos da corrente da história. ${ }^{36}$

\section{Um olhar em perspectiva}

Na direção do que afirma Fitzmyer, "hoje é impossível alguém voltar a um método pré-crítico de interpretar a Bíblia" ${ }^{37}$. Contudo, não há espaço para ufanismos. Até porque há sinais de um certo esgotamento dos recursos do método. A compreensão de que o método histórico-crítico havia chegado para resgatar o estudo da Bíblia da escuridão e "esclarecer, mediante o uso metódico da razão, a confusão reinante entre Palavra de Deus e Escritura, para separar a verdade do erro, a fé da superstição" ainda carece de discussão e aprofundamento.

Da mesma forma, a "crença de que toda verdadeira pesquisa, em qualquer área do conhecimento humano, pode ser feita de maneira isenta e neutra" mostrou-se infundada. A ideia de que o "cientista e o pesquisador podem neutralizar suas pré-convicções ou pressuposições e aproximar-se vazios do objeto de estudos, abertos para formar novas convicções a partir dos dados e das evidências achados"38 não é sustentável diante da compreensão que hoje se tem de ciência.

Antes de bater o martelo sobre o assunto, é preciso considerar que o que acontece com o acesso à Bíblia com o método histórico-crítico é reflexo de um processo mais amplo, que tem o seu espelho nas mudanças da Modernidade. É nesse contexto

\footnotetext{
34 TROELTSCH, 1984, p. 5.

35 TROELTSCH, 1984, p. 6.

36 TROELTSCH, 1984, p. 7.

37 FITZMYER, 1997, p. 27.

38 LOPES, 2005, p. 120.
} 
que as questões relacionadas com a relação entre fé e razão também reverberam para dentro dos estudos bíblicos. E, no entanto, o entendimento ao qual se chega na atualidade é que as alternativas propostas para a relação entre fé ou razão não solucionam a questão colocada. Nem exclusão nem fusão são alternativas para fé ou para ciência. Afinal, tanto o saber, afirmado pela razão quanto o crer, sustentado pela fé, são importantes para a vida das pessoas e para o acercamento à Bíblia.

$\mathrm{O}$ esforço por proteger a Bíblia de um exame crítico, questionando uma aproximação científica, está diretamente relacionado com o fim do domínio secular exercido pela igreja por séculos e a necessidade de redefinir o papel da religião na sociedade e, de modo particular, da verdade bíblica.

Ninguém pode ser contra uma compreensão sustentável da Bíblia. Nesse sentido, a fé deveria estar em condições de responsabilizar seu discurso frente ao foro crítico da razão. Contudo, é preciso reconhecer que a ciência bíblica também exagerou na crítica, fazendo com que o criticismo bíblico fosse sentido como sacrilégio, por vezes, violência pura contra o texto sagrado cristão. ${ }^{39}$

Também é preciso considerar que, não obstante a exposição da Bíblia ao tratamento histórico-crítico, "a Bíblia não é e não quer ser um livro de ciências" ${ }^{40}$. Da mesma forma, Antigo e Novo Testamento, por mais elementos históricos e críticos que possam ser encontrados neles, não são simples registros históricos, muito menos no sentido positivista como, muitas vezes, o conceito de História é compreendido. Qualquer tentativa de compreensão do texto bíblico que não leve em conta que se trata de um livro de fé, testemunho da experiência de fé de um povo com seu Deus, na história, certamente não estará dando o devido tratamento ao seu objeto de investigação, por mais científico que seja o método.

Além de considerar a dimensão histórica do texto bíblico, a crítica histórica também permite levar a sério a condição dos autores como testemunhas humanas, sujeitas a certos condicionamentos, preferências e até mesmo inexatidões. ${ }^{41}$ Ao propor interpretar o texto em seu contexto histórico, o método resguarda o texto de interpretações desconectadas da realidade histórica, do horizonte da vida. Além disso, há que considerar que os métodos científicos foram aperfeiçoados no estudo de textos da antiguidade.

Como primeiro ponto a ser destacado, vale resgatar o que já foi afirmado no século passado por pesquisadores da Comissão Bíblica Católica, a saber: "reconhece que o método histórico-crítico, 'utilizado de maneira objetiva', não implica em si nenhum a priori". O texto da Comissão Bíblica completa a informação dizendo que se há algum a priori, isso não se deve ao método, mas aos pré-conceitos ou pressupostos de quem o emprega. ${ }^{42}$

Outro argumento utilizado pela Comissão Bíblica Católica aponta para uma constatação que se faz cada vez mais atual, principalmente em vista da emergência de

\footnotetext{
${ }^{39}$ Acerca dos exageros, ver BRAKEMEIER, Gottfried. A Autoridade da Bíblia. São Leopoldo: Sinodal; CEBI, 2007. p. 47.

${ }^{40}$ BRAKEMEIER, 2007, p. 54.

${ }^{41}$ WEGNER, 1998, p. 19.

${ }^{42}$ FITZMYER, 1997, p. 33.
} 
novas ferramentas disponíveis para o estudo da Bíblia. Trata-se do entendimento de que "nenhum método científico pode trazer à luz todas as riquezas do texto bíblico"43. Nessa mesma direção, entende-se que "hoje não se espera que o método nos conduza às verdades eternas da mensagem definitiva de Deus"

Como afirma Ely Éser Barreto, uma tentação no uso do instrumental do método histórico-crítico consiste em querer "tornar objetivos de tal modo os elementos fundantes da fé, que a fé se torne um fenômeno controlado pela racionalidade humana" ${ }^{45}$.

É na relação entre fé e ciência, palavra humana e palavra de Deus, que o método histórico-crítico mais dá o que pensar. $\mathrm{O}$ equacionamento entre os pressupostos teóricos, a matriz epistemológica e os procedimentos exegéticos constituem um dos maiores desafios colocados, não apenas ao método histórico-crítico, mas ao próprio entendimento da Escritura cristã na atualidade.

Como também já foi destacado na produção literária sobre o método histórico-crítico, ele é refratário ao universo popular de leitura da Bíblia. Dada a erudição que pressupõe, em boa medida, permanece exclusividade de uma elite. Sua natureza científica contribuiu para um distanciamento entre o mundo acadêmico e a realidade eclesial. Nesse sentido, são procedentes as críticas de Eta Linnemann, Eugen Drewermann, dentre outros. ${ }^{46}$ De fato, o historicismo exagerado por vezes parece afastar da fé, da oração e do respeito pela Bíblia. Da mesma forma, uma crítica entendida de forma negativa, como atitude de aversão e de intenção destrutiva, somente conduzirá o esforço de compreensão do texto bíblico ao fracasso.

A questão fundamental continua sendo qual o tipo de abordagem a própria Bíblia reivindica para sua adequada compreensão e interpretação. Partindo do princípio de que o tratamento de qualquer documento deve ser adequado à sua natureza, $\mathrm{o}$ tratamento dispensado à Bíblia não deveria ser exceção a essa regra.

Conforme destaca Gottfried Brakemeier, a compreensão dos textos bíblicos não está atrelada ao uso do instrumental histórico crítico ou dependa de especialistas. Contudo, o emprego do instrumental de análise histórico-crítica da Bíblia está a serviço de valiosos objetivos, dentre os quais se destacam:

Estudo crítico da Bíblia procura evitar o que poderíamos chamar de "esquizofrenia" intelectual, ou seja, o lado a lado conflituoso do mundo da fé e da ciência.

A análise histórico-crítica da Bíblia está a serviço da autenticidade da fé. Procura distinguir o essencial do periférico. Vai insistir que o ser humano não é salvo pelo conhecimento. Não é a aceitação da "cosmovisão bíblica" que justifica o ser humano. Exegese histórico-crítica vai mostrar os condicionamentos contextuais, culturais, históricos dos textos bíblicos e destilar, exatamente assim, o evangelho ${ }^{47}$.

${ }^{43}$ FITZMYER, 1997, p. 37.

${ }^{44}$ CÉSAR, Ely Éser Barreto. O método histórico-crítico Hoje. In: VOLKMANN; DOBBERAHN; CÉSAR, 1992, p. 89.

${ }^{45}$ CÉSAR, 1992, p. 78.

${ }^{46}$ LINNEMANN, Eta. Crítica Histórica da Bíblia. São Paulo: Cultura Cristã, 2009. Augusto Nicodemos Lopes faz uma relação de pesquisadores que têm se ocupado com a crítica ao método (LOPES, 2005, p. 116).

${ }^{47}$ BRAKEMEIER, 2007, p. 56. 
Por fim, resta dizer que, não obstante as críticas ao método, a possibilidade de abuso dos recursos de que lança mão, existe espaço para o método histórico-crítico na igreja e na academia. Importa discernir. A falta de consenso entre especialistas, como observa Brakemeier, não é argumento para desdenhar da análise científica da Bíblia. ${ }^{48}$ Não são os resultados da pesquisa científica que conduzem à fé ou devam ser cridos. Quando o assunto é Bíblia, ciência e fé também podem conviver por meio da análise histórico-crítica da Escritura.

\section{Referências}

BRAKEMEIER, Gottfried. A autoridade da Bíblia. São Leopoldo: Sinodal; CEBI, 2007.

BULTMANN, Rudolf Karl. Die Geschichte der Synoptischen Tradition. 7. Durchgesehene Aufl. Göttingen: Vandenhoeck \& Ruprecht, 1967.

CARSON, D. A. A exegese e suas falácias. São Paulo: Vida Nova, 1992.

DIBELIUS, Martin. Die Formengeschichte des Evangeliums. 3. Durchges. Aufl. mit einem Nachtrag von Gerhard Iber ed. Tübingen: J. C. Mohr, 1959.

EGGER, Wilhelm. Metodologia do Novo Testamento: Introdução aos Métodos Linguísticos e Histórico-Críticos. São Paulo: Loyola, 1994.

FITZMYER, Joseph A. A Bíblia na Igreja. São Paulo: Loyola, 1997. (Bíblica Loyola; 21).

FITZMYER, Joseph A. A Interpretação da Escritura: em Defesa do Método Histórico-Crítico.

São Paulo: Loyola, 2011. (Bíblica Loyola; 58).

GUNKEL, Hermann. Genesis. 6. Aufl. Berlin: Evangelische Verlagsanstalt, 1963.

JUNGES, Fábio César; KONZEN, Leo. O método histórico-crítico de Interpretação bíblica. Vivências, Santo Ângelo, v. 4, n. 5, p. 101-113, out. 2007.

KIRST, Nelson; DOBBERAHN, Friedrich Erich. Introdução aos métodos exegéticos. São Leopoldo: Faculdade de Teologia, 1985.

LINNEMANN, Eta. Crítica histórica da Bíblia. São Paulo: Cultura Cristã, 2009.

LOPES, Augustus Nicodemus. A Bíblia e seus Intérpretes. Uma breve história da Interpretação. São Paulo: Cultura Cristã, 2004.

LOPES, Augustus Nicodemus. O Dilema do método histórico-crítico na Interpretação Bíblica. Fides Reformata, São Paulo, ano X, n. 1, p. 115-138, 2005.

MESTERS, Carlos. O CEBI e sua metodologia de leitura bíblica. Por Trás da Palavra, v. 11, n. 64, p. 25-36, 1991.

NETO, João Oliveira Ramos. Os Problemas e os Limites do Método Histórico-Crítico. Theos, Campinas, 6. ed., v. 5, n. 2, p. 1-12, dezembro de 2009.

PONTIFÍCIA COMISSÃO BÍBLICA. A interpretação da Bíblia na Igreja. São Paulo: Loyola, 1994.

RICOEUR, Paul. Da Interpretação: ensaio sobre Freud. Rio de Janeiro: Imago, 1977.

SÁNCHEZ VÁSQUEZ, Adolfo. Ética. 3. ed. Rio de Janeiro: Civilização Brasileira, 1978.

TROELTSCH, Ernst. Sobre o Método Histórico e Dogmático da Teologia. São Leopoldo: Faculdade de Teologia, 1984.

VOLKMANN, Martin; DOBBERAHN, Friedrich Erich; CÉSAR, Ely Éser Barreto. Método histórico-crítico. São Paulo: CEDI, 1992. (Leituras da Bíblia 4).

${ }^{48}$ BRAKEMEIER, 2007, p. 55. 
WEGNER, Uwe. A leitura bíblica por meio do método sociológico. São Paulo: CEDI, 1993. (Mosaicos da Bíblia; 12). Disponível em: <http://koinonia.org.br/protestantes/uploads/novidades/ Mosaicos-da-biblia_012.pdf >. Acesso em: 30 jul. 2019.

WEGNER, Uwe. Exegese do Novo Testamento: Manual de Metodologia. São Leopoldo: Sinodal, 1998. 